\title{
Reactivity of calcium carbonate prepared from flue gas desulfurization gypsum
}

\author{
Jana Jurišováa, Vladimír Danielik ${ }^{a}$, Pavel Fellnera, \\ Milan Králik $k^{a}$, Tomáš Foltinovič ${ }^{b}$ \\ ${ }^{a}$ Faculty of Chemical and Food Technology, Slovak University of Technology in Bratislava, \\ Radlinského 9, 81237 Bratislava, Slovakia \\ ${ }^{b}$ Research Institute of Chemical Technology, VUCHT a.s., \\ Nobelova 34, 83603 Bratislava, Slovakia \\ jana.jurisova@stuba.sk
}

\begin{abstract}
Reactivity of various calcium carbonate samples for flue gas desulfurization was tested. Two groups of $\mathrm{CaCO}_{3}$ samples were considered; natural limestone containing calcite phase dominantly and samples prepared by the conversion of gypsum with ammonium and carbon dioxide (precipitated $\mathrm{CaCO}_{3}$ ) containing different amounts of calcite, aragonite and vaterite.

Reactivity of precipitated calcium carbonate depends primarily on the particle size, similarly as in case of industrial samples. The initial reaction rate was comparable with the industrial limestones for samples with the average particle size lower than $15 \mu \mathrm{m}$. However, the conversion of laboratory samples was significantly higher after 5 min of the reaction.

Phase composition of the precipitated calcium carbonate has a minor but noticeable impact on the reactivity. The presence of vaterite slightly increased the reactivity, which is in accordance with its lower compact structure in comparison with calcite and aragonite. Unexpected effect of the increased content of aragonite, which is the most compact phase in comparison with calcite and vaterite, was observed. If calcium carbonate contains up to approximately $30 \%$ of aragonite the reactivity increases, which can be explained by the SEM pictures showing agglomerate composition with relatively high specific surface. At higher contents of aragonite, the reactivity decreases. All the obtained results proved the suitability of precipitated $\mathrm{CaCO}_{3}$ prepared from flue gas desulfurization gypsum to be recycled in the flue gas desulfurization process.
\end{abstract}

Keywords: flue gas desulfurization, $\mathrm{CaCO}_{3}$ reactivity, aragonite, calcite, vaterite

\section{Introduction}

Fossils fuels are still the main energetic source. Endeavour for minimizing the exploitation of fossil fuels is evident but coal will remain important at least until 2050 (BP Energy outlook 2018 Edition; Exxon Mobil, 2018; EU Reference Scenario 2016). Besides other impurities, various sources of coal contain from 0.1 up to $4 \%$ of sulfur which generates $\mathrm{SO}_{2}$ during coal combustion. Harmful effects of $\mathrm{SO}_{2}$ on living organisms are generally known and therefore treatment of flue gass is necessary (IEA 2016). Recently, desulfurization techniques have been summarized showing the wet limestone procedure to be one of the most frequently used (Králik et al., 2017). Wet flue gas desulfurization (FGD) provides one of the highest efficiencies of $\mathrm{SO}_{2}$ removal. This method is highly reliable (Zhong et al., 2008) and belongs to the least expensive ones to operate (Olausson et al., 1993). The efficiency and reliability of this technology has improved considerably in the past 20 years (Dou et al., 2009) and combined with other purifying processes significantly decreased the harmful effects of flue gases from coal power plants.

The product of desulfurization technology is gypsum. Properties and utilization of gypsum were well described by Wirsching (2000); prefabricated gypsum building components, gypsum plaster and gypsum constructing materials generally, are its main application areas (about $70 \%$ ). Another possibility is to use gypsum as a fertilizer; directly as a water suspension or a raw material for the production of other sulfur containing fertilizers, mainly in form of ammonium sulfate and blends containing it (Králik et al., 2017; Jang et al., 2014). Ammonium sulfate can be prepared by the conversion reaction of gypsum with $\mathrm{CO}_{2}$ and ammonia (Danielik et al., 2018). Except for ammonium sulfate, calcium carbonate is produced as a by-product which can be recycled back to the FGD process (Jang et al., 2001; CN101337684A). In this case it is important to know the reactivity of produced calcium carbonate in the FGD process.

Understanding of the limestone dissolution/reaction kinetics of the FGD processes has attracted quite serious attention (Siagi and Mbarawa, 2009; Toprac and Rochelle, 1982; De Blasio et al., 2012; Ye and Bjerle, 1994; Ahlbeck et al., 1993; Ahlbeck et al., 1995; Pepe, 2001; Ukawa et al., 1993; Chan and Rochelle, 1982; Shih et al., 2000). It is assumed that limestone dissolution is the rate controlling step of $\mathrm{SO}_{2}$ absorption processes (Siagi and Mbarawa, 
2009; Pepe, 2001). When $\mathrm{SO}_{2}$ diffuses into the liquid phase its hydrolysis takes place and hydrogen ions are produced. These ions are neutralized by the dissolved limestone. When limestone is added into water, it dissolves to a low extent (Ahlbeck et al., 1993; Ahlbeck et al., 1995). Considering the carbonate and bicarbonate equilibrium, the dissolution of limestone is enhanced under acidic conditions. According to Wallin and Bjerle (1989), the limestone dissolution rate in low $\mathrm{pH}$ environments is mass transfer controlled; the diffusion of hydroxonium ions is crucial. At higher $\mathrm{pH}$, kinetics of the reaction on the limestone surface prevails. Ukawa et al. (1993) reported a method for measuring the rate of limestone dissolution in both batch and continuous reaction systems. They used continuous measuring of the particle size distribution during the reaction and obtained a good agreement with a model based on the mass transfer. It is commonly accepted that particle size distribution, limestone composition and its origin are the limestone characteristics determining its reactivity in the FGD process.

Reactivity of limestone can be determined by different methods. Measurements showed reactivity dependence on $\mathrm{pH}$, particle size and reactor volume. Reactivity of several types of limestones used in FGD measured as neutralization rate with strong and weak acids at constant and/or varying pH was presented by Stumpf et al. (1984a, b). A detailed analysis of the methods characterizing limestone samples and their reactivity was summarized by Brown et al. (2009). The most accurate measurement of limestone reactivity in the flue gas desulfurization process can be achieved with a suspension of the ground limestone and $\mathrm{SO}_{2}$ containing gas. However, tests with mineral acids (Ahlbeck et al., 1995; Fellner and Khandl, 1999; De Blasio et al., 2012; Stumpf et al. 1984a, b) proved the validity of "the $\mathrm{pH}$ constant method" for the estimation of limestone reactivity. In this method, a suspension of limestone is titrated with a mineral acid solution $\left(\mathrm{H}_{2} \mathrm{SO}_{4}\right.$ or $\left.\mathrm{HCl}\right)$ at virtually constant $\mathrm{pH}$ chosen from the range of 4 to 5 . Time dependence of added acid as well as reaction rates at certain time points are evaluated. This titration is much more reproducible than bubbling of an $\mathrm{SO}_{2}$ containing gas through the slurry of limestone. It is possible to compare reactivity of various limestone samples easily. For this reason, we have also used this method in our tests.

All the above mentioned papers deal with natural (mineral) limestones, typically with calcite phase as the dominant one. Calcium carbonate precipitated during the reaction of gypsum with $\mathrm{CO}_{2}$ and ammonia may show different reactivity, mainly due to the different crystallographic modification of calcium carbonate. A comparison of the reactivity and properties of limestone and calcium carbonate precipitate consisting of calcite was presented by Dragan and Ozunu (2012). Reactivity strongly depends on the particle size, the difference between the limestone and calcium carbonate precipitate was negligible. However, the influence of different crystallographic modifications of calcium carbonate (calcite, aragonite, vaterite) has not been thoroughly studied for the purposes of FGD.

In this paper, reactivity of calcium carbonate prepared by the conversion reaction of gypsum and with varying content of calcite, aragonite and vaterite was studied. The reactivity was compared considering the phase composition, particle size distribution and specific surface area.

\section{Materials and Methods}

Nine laboratory samples of limestone prepared by the conversion of FGD gypsum with $\mathrm{NH}_{3}$ and $\mathrm{CO}_{2}$ in water solution were tested. Their reactivity was compared with: (i) ground natural mineral sample LietLuc, (ii) precipitated limestone from paper industry Monkal. Content of $\mathrm{CaCO}_{3}$ was above $90 \%$ in all samples. Samples LietLuc and Monkal consisted mainly of calcite. Laboratory samples contained different amounts of aragonite, calcite and/or vaterite. Average particle size in all samples was in the range of $(10-25) \mu \mathrm{m}$.

The BET specific surface area was calculated from nitrogen adsorption isotherms at $-196{ }^{\circ} \mathrm{C}$ using ASAP-2400 (Micromeritics, Norcross, USA). Degasification was carried out for 24 hours at $80^{\circ} \mathrm{C}$ and $2 \mathrm{kPa}$. Reproducibility of measurements derived from three repetitions was $\pm 7 \%$ related to specific surface area calculated from the BET isotherm.

Particle size distribution was measured using a CILAS 930 Liquid laser diffraction granulometer. Water was used as the liquid phase; ultrasound was applied to disorder solid agglomerates. Morphology of the specimens was observed using a scanning electron microscope (SEM) ZEISS ZVO 40 coupled to an energy dispersive X-ray spectrometer analyzer (EDX) Bruker AXS.

Reactivity tests were performed as follows: about $1.500 \mathrm{~g}$ of dried powder calcium carbonate sample were added to $200 \mathrm{ml}$ of deionized water and stirred by a magnetic stirrer $(500 \mathrm{rpm})$ for $5 \mathrm{~min}$ at laboratory temperature $(25 \pm 0.5)^{\circ} \mathrm{C}$ in order to disintegrate the formed agglomerates. Then, the suspension was titrated with $1 \mathrm{M} \mathrm{HCl}$ at constant $\mathrm{pH}$ equal to 4 . The control of $\mathrm{pH}$ was provided by a control loop consisting of a pH electrode, computer and a switcher controlling the peristaltic pump dosing the solution of HCl. Dependence of the 
amount of added $\mathrm{HCl}$ on time was monitored every second. The maximum length of an experiment was $60 \mathrm{~min}$. Conversion of limestone was calculated with respect to the total weight of the sample. Three parallel measurements were carried out.

\section{Results and Discussion}

Characteristics of all samples are summarized in Tables 1 and 2. Laboratory samples have Gauss-like distribution of the particle size, i.e. the size distribution of unimodal type. Industrial samples LietLuc and Monkal showed several Gauss-like peaks in the particle size distribution, i.e. they represent multimodal type of size distribution (three-modal in this case).

In Fig. 1, SEM figures of the laboratory samples are presented. It can be seen that the particle size of samples CC1-CC5 is lower than that of the other samples, which is in accordance with the particle size distribution. However, the particles are of dif- ferent shape due to the different phase composition of the samples. Needles of aragonite may significantly increase the particle surface. On the other hand, calcite particles may form conjunct crystals, which results in the formation of large particles.

A comparison of the time dependencies of calcium carbonate conversion is shown in Figs. 2 and 3. It can be seen that the initial reaction rate of the laboratory samples with small particles (CC1-CC4) is comparable with the reaction rate of the industrial samples. However, the reaction rate of industrial samples decreased after a short initial time (ca $5 \mathrm{~min}$ ), probably due to the multimodal particle size distribution and complete conversion of the smallest particles. Moreover, the effect of dolomite present in Lietluc and Monkal samples can also decrease the reaction rate. After 10 minutes of the reaction, conversion of samples CC1-CC4 was above $70 \%$. This is the point when the reaction rate of the industrial samples is at one level with laboratory samples containing large particles (CC5-CC9).

Tab. 1. Particle size distribution and specific surface area of samples.

\begin{tabular}{|c|c|c|c|c|c|}
\hline & \multicolumn{4}{|c|}{ Particle size $[\mu \mathrm{m}]$} & \multirow{2}{*}{$\begin{array}{c}\text { Specific surface } \\
\text { area }\left[\mathrm{m}^{2} / \mathrm{g}\right]\end{array}$} \\
\hline & Diameter at $10 \%$ & Diameter at $\mathbf{5 0} \%$ & Diameter at $90 \%$ & Mean diameter & \\
\hline CC1 & 1.9 & 9.51 & 18.03 & 9.9 & 2.52 \\
\hline CC2 & 2.66 & 10.12 & 17.66 & 10.3 & 4.84 \\
\hline CC3 & 3.56 & 13.87 & 23.55 & 14.02 & 2.89 \\
\hline CC4 & 2.41 & 11.93 & 21.65 & 12.46 & 2.66 \\
\hline CC5 & 2.21 & 13.38 & 28.09 & 14.63 & 1.64 \\
\hline CC6 & 12.15 & 23.63 & 41.78 & 25.55 & 1.54 \\
\hline $\mathrm{CC} 7$ & 10.7 & 23.55 & 41.79 & 25.14 & 2.55 \\
\hline CC8 & 7.54 & 18.93 & 34.82 & 20.18 & 1.29 \\
\hline CC9 & 11.88 & 22.00 & 34.37 & 22.67 & 0.43 \\
\hline LietLuc & 1.68 & 8.58 & 45.56 & 16.31 & - \\
\hline Monkal & 2.19 & 16.46 & 42.68 & 20.10 & - \\
\hline
\end{tabular}

Tab. 2. Phase composition of samples.

\begin{tabular}{lcccc}
\hline & \multicolumn{2}{c}{ Composition [ \%] } & \\
& Calcite & Aragonite & Vaterite & Dolomite \\
\hline CC1 & 68.0 & 27.1 & 0.0 & 3.8 \\
CC2 & 38.0 & 54.2 & 0.0 & 3.3 \\
CC3 & 1.6 & 2.6 & 91.0 & 3.7 \\
CC4 & 1.0 & 0.0 & 93.3 & 3.9 \\
CG5 & 50.0 & 10.2 & 35.0 & 3.7 \\
CC6 & 1.0 & 90.0 & 0.0 & 3.7 \\
CC7 & 0.2 & 95.7 & 0.0 & 3.7 \\
CC8 & 11.0 & 7.8 & 75.3 & 3.9 \\
CC9 & 92.3 & 2.2 & 0.0 & 3.8 \\
LietLuc & 91.4 & 0.0 & 0.0 & 6.5 \\
Monkal & 94.6 & 0.0 & 0.0 & 2.4 \\
\hline
\end{tabular}


a)

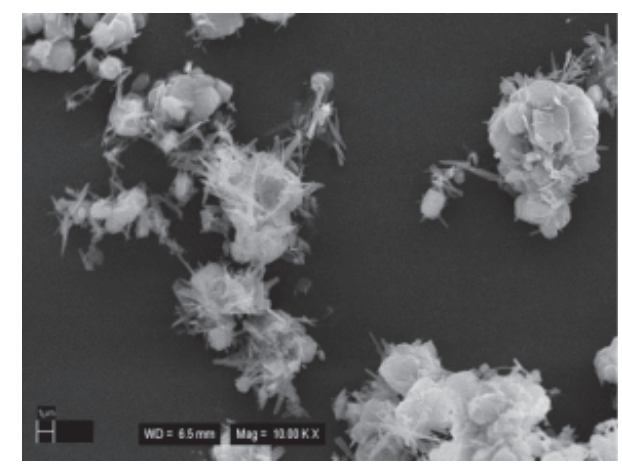

c)

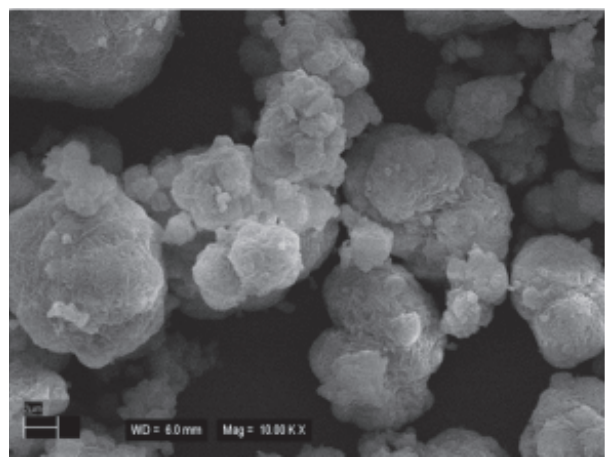

e)

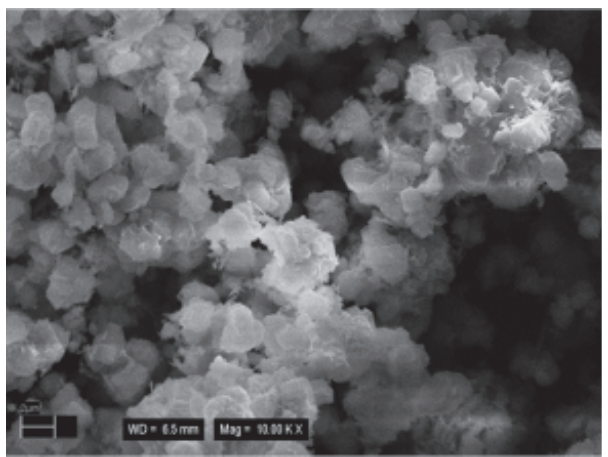

g)

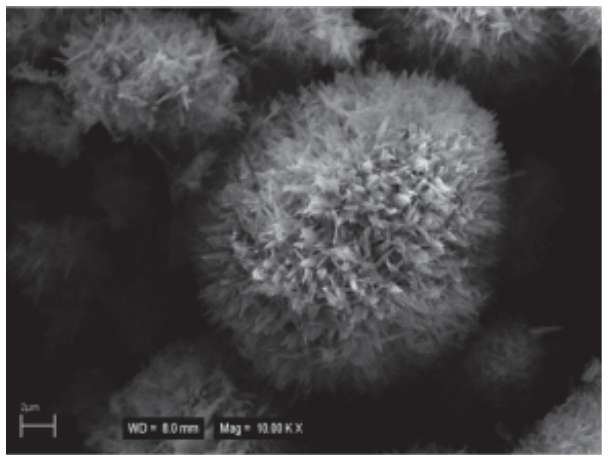

b)

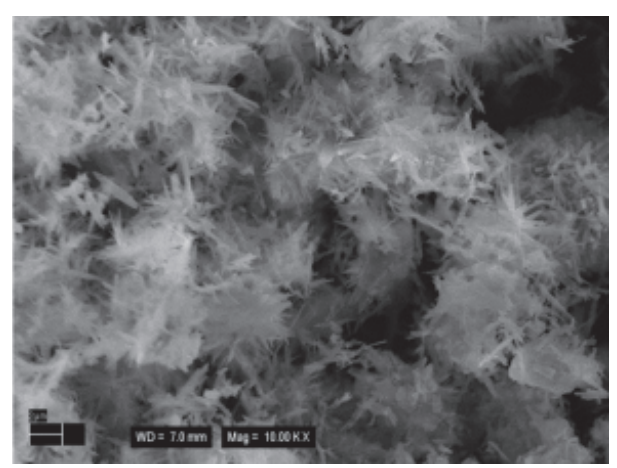

d)

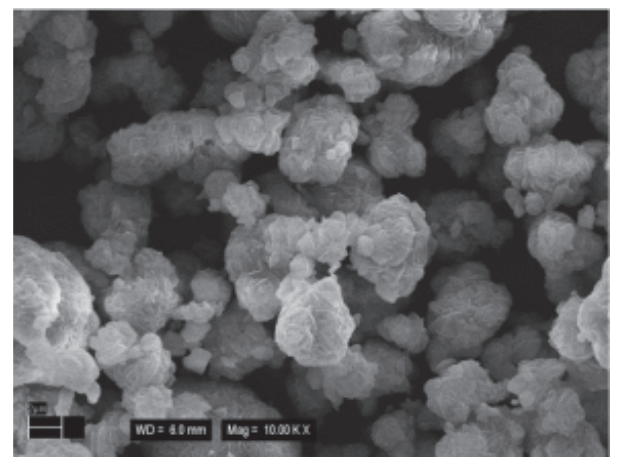

f)

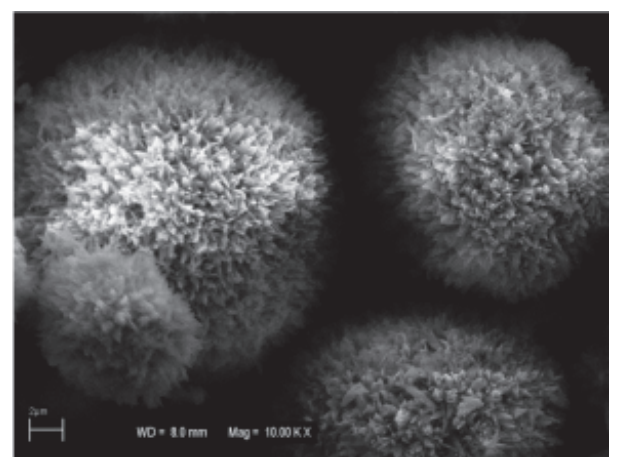

h)

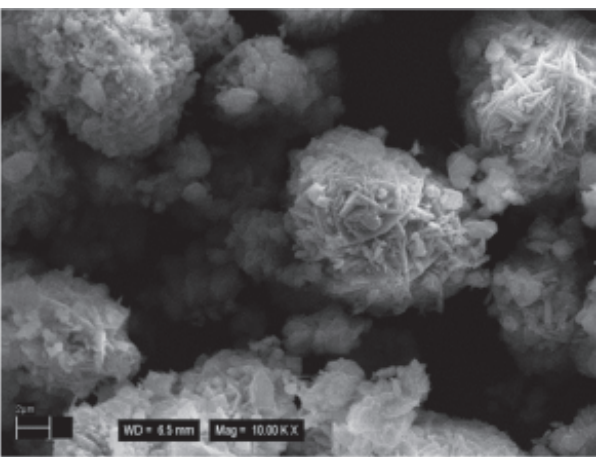

i)

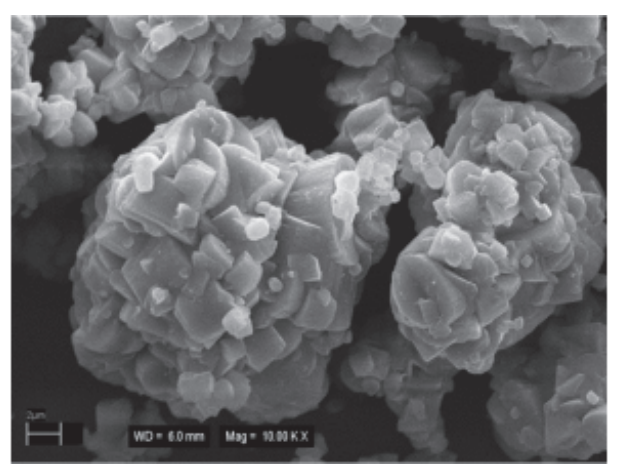

Fig. 1. SEM records of precipitated laboratory calcium carbonate samples. a) CC1; b) CC2; c) CC3; d) CC4; e) CC5; f) CC6; g) CC7; h) CC8; i) CC9. 


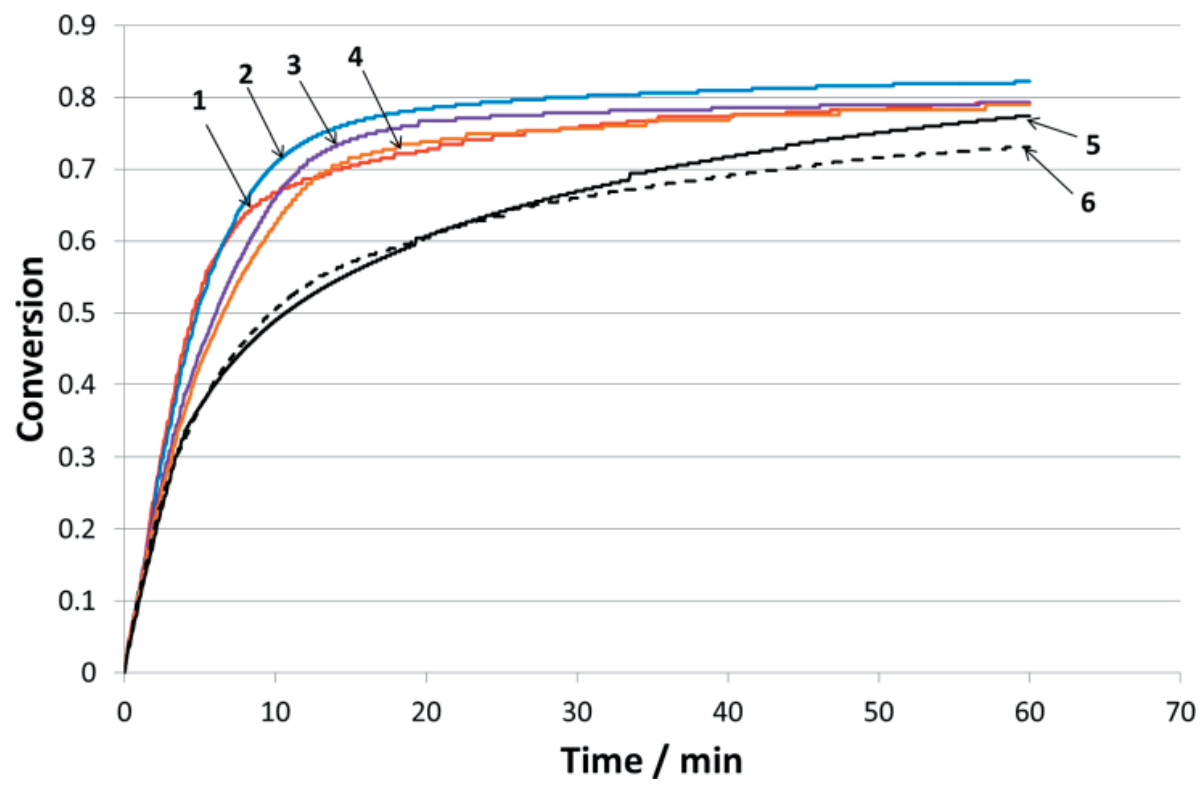

Fig. 2. Time dependence of the conversion of samples CG1 (1); CC2 (2); CC3 (3); CC4 (4); LietLuc (5); Monkal (6).

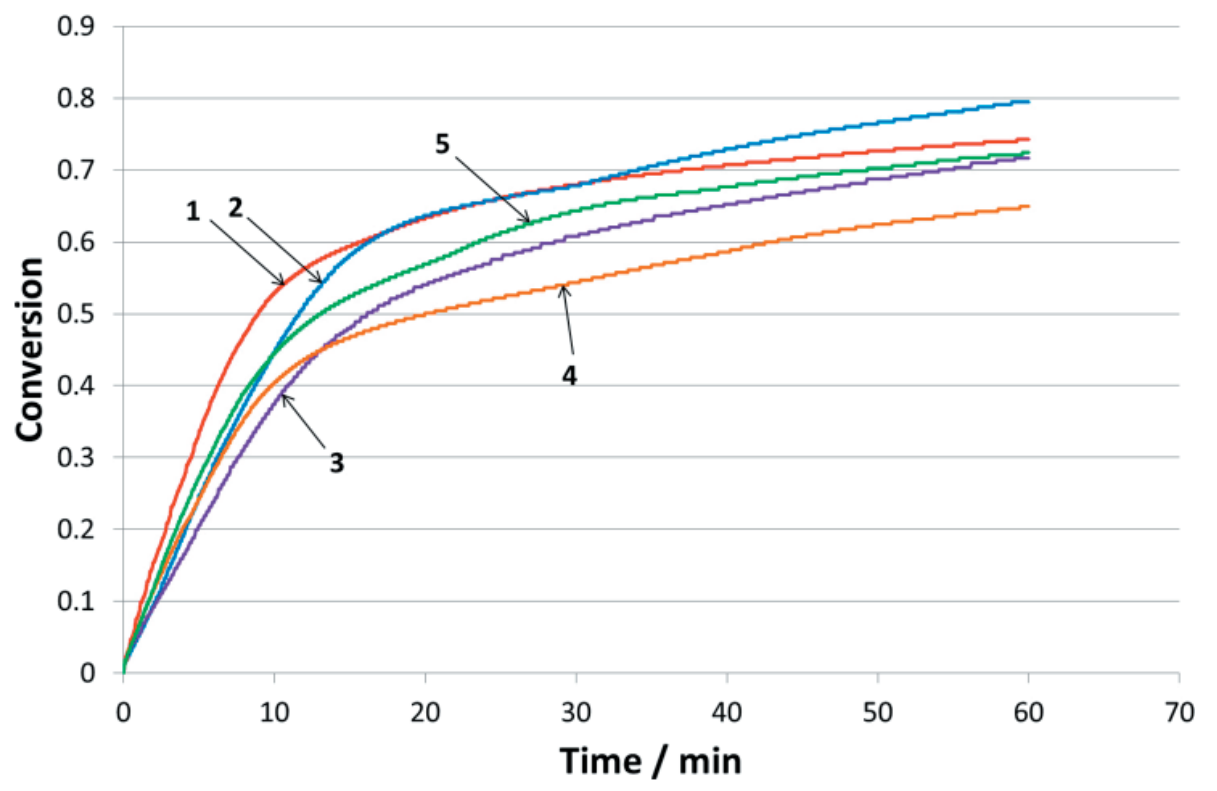

Fig. 3. Time dependence of the conversion of samples CC5 (1); CC6 (2); CC7 (3); CC8 (4); CC9 (5).

Detailed comparison of the reactivity of laboratory samples was carried out $3 \mathrm{~min}$ and $15 \mathrm{~min}$ after the beginning of the reaction. The initial reaction rate can be studied at the time of $3 \mathrm{~min}$ while $15 \mathrm{~min}$ after the reaction beginning, the conversion is above $50 \%$ and the reaction rate significantly decreases compared to the initial one. The comparison is shown in Fig. 4. As it can be seen, the conversion correlates very well with the average size of the particles and with the parameter diameter at $90 \%$ (Fig. 4a) 3 minutes after the reaction beginning. Later (15 min), the correlation is satisfactory for the diameter at $90 \%$ (Fig. 4b). It can be assumed that small particles completely reacted at this time and the size of the large particles is decisive. On the other hand, there is only a slight correlation between the reaction rate and the specific surface area of the samples, which is in accordance with the published data (Ahlbeck et al., 1993; Ahlbeck et al., 1995; Ukawa et al., 1993; Wallin and Bjerle, 1989; Dragan and Ozunu, 2012; Claudio A. Carleti G., 2015).

Good correlation of the reaction rate and the particle size indicates that the influence of aragonite and vaterite is not crucial for the initial reaction rate. However, the impact of different solid phases can prove to be of increasing importance at higher conversion of $\mathrm{CaCO}_{3}$. 

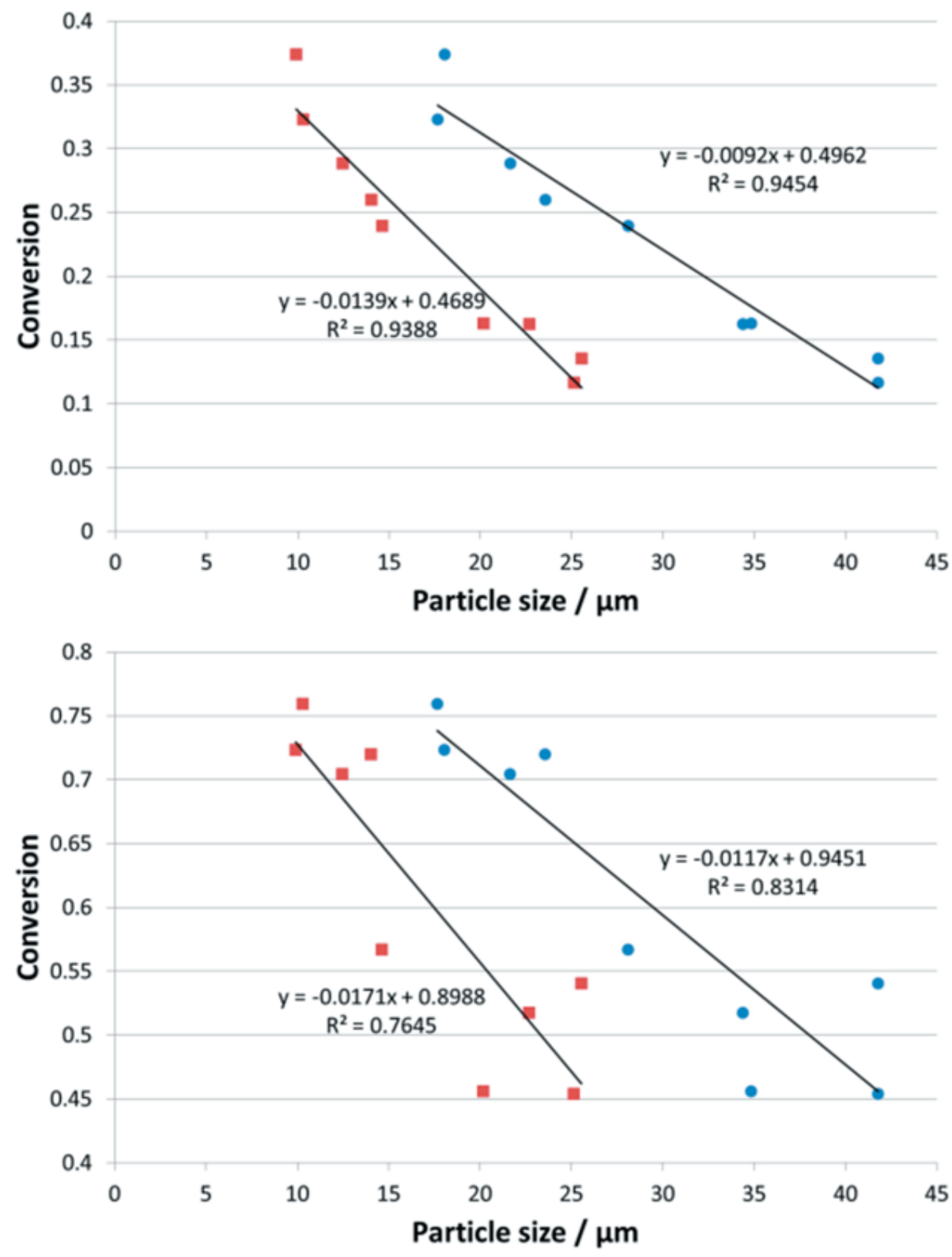

Fig. 4. Conversion of samples CC1-CC9 vs. particle size in 3 min (upper) and 15 min (bottom). (squares): mean diameter; (circles): diameter at $90 \%$.

It is assumed that limestone dissolution is the rate controlling step (Siagi and Mbarawa, 2009; Pepe, 2001). Based on the solubility products shown in Table 3, vaterite is more soluble and the reaction rate should increase, which is in accordance with our experimental data when higher content of vaterite resulted in increased reaction rate (Fig. 5a). The influence of aragonite content is not so obvious as its solubility is slightly higher than that of calcite. If calcium carbonate consists of calcite with a portion of aragonite, the reactivity increases. Besides the higher solubility of aragonite, morphology of the particle surface may be reflected in the reactivity. As it can be seen in Figs. 1a and 1b, needles of aragonite grow from the calcite particles and the particle surface is significantly larger while their size is still small. On the other hand, when calcium carbonate consists mainly of aragonite, the particles are huge and solid (Figs. If and $1 \mathrm{~g}$ ). Therefore, the reactivity of calcium carbonate with high content of aragonite is lower compared

Table 3. Solubility products of aragonite, calcite and vaterite

\begin{tabular}{ccc}
\hline Aragonite & Calcite & Vaterite \\
\hline $\mathrm{K}_{\mathrm{s}}=6.0 \times 10^{-9}$ & $\mathrm{~K}_{\mathrm{s}}=3.3 \times 10^{-9}$ & $\mathrm{~K}_{\mathrm{s}}=1.3 \times 10^{-8}$ \\
$($ Plummer and Busenberg, 1982) & $($ Benjamin, 2002) & (Plummer and Busenberg, 1982) \\
\hline
\end{tabular}




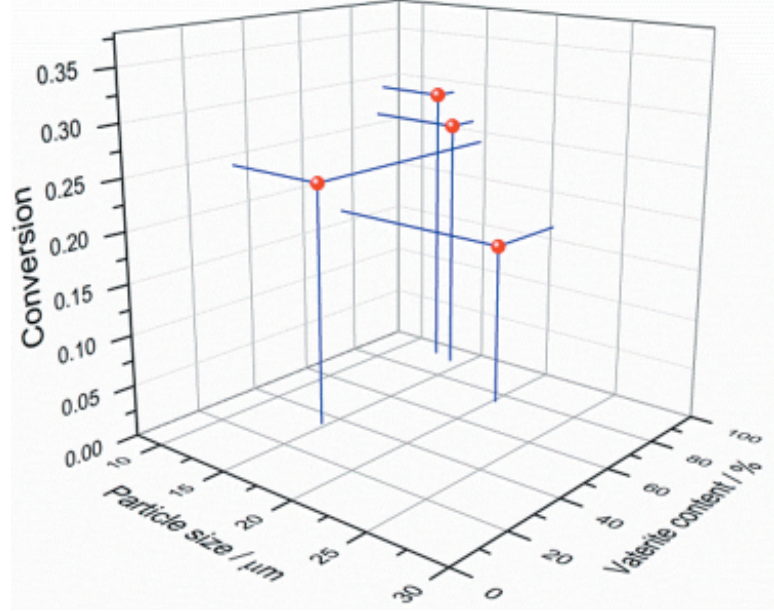

a)

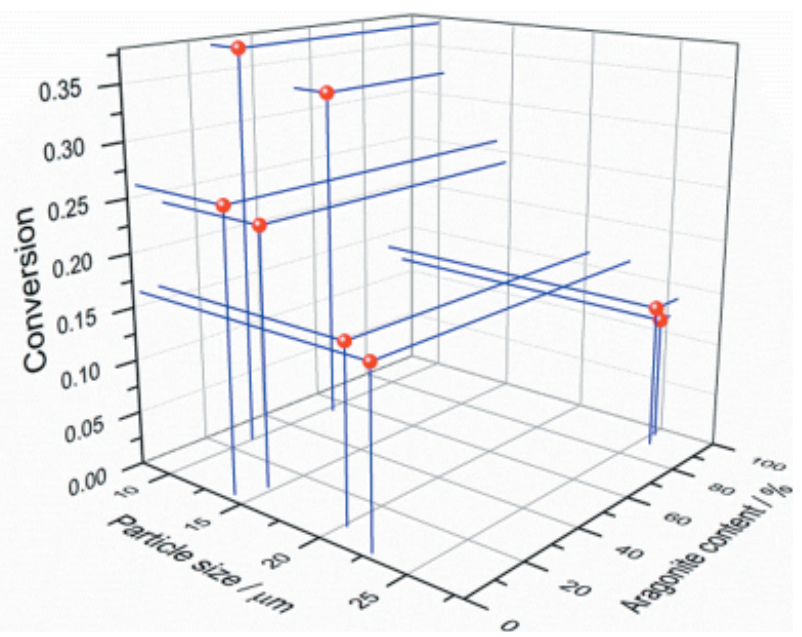

b)

Fig. 5. Conversion of samples CC1-CC9 in 3 min vs. particle size and content of vaterite (a) and aragonite (b).

to that containing calcite. This has also been proven experimentally. The reactivity of calcium carbonate containing aragonite and calcite increases up to $30 \%$ of aragonite then it decreases (Fig. 5b).

\section{Conclusions}

Calcium carbonate samples prepared by the conversion reaction of FGD gypsum with $\mathrm{CO}_{2}$ and ammonia were tested. Their reactivity was determined for the purpose of flue gas desulfurization and compared with the ground natural mineral (industrial) samples. The comparison showed that such prepared calcium carbonate is suitable for the FGD process and it can be recycled. The side product from the conversion of FGD gypsum is ammonium sulfate, which is a very valuable fertilizer compound.

In case of industrial samples, the reactivity of precipitated calcium carbonate depends primarily on the particle size. If the particle size is below $15 \mu \mathrm{m}$, the initial reaction rate is comparable with industrial limestones. After a short initial time, the reaction rate of industrial limestones significantly decreases while the reaction rate of precipitated samples remains high.

Phase composition of the precipitated calcium carbonate has a minor impact on the reactivity. The presence of vaterite slightly increases the reactivity. If calcium carbonate contains up to approximately $30 \%$ of aragonite, the reactivity increases while it decreases at higher contents of aragonite.

\section{Acknowledgement}

This work was supported by the Slovak Research and Development Agency under the contract NO. APVV-14-
0217 (Exploitation of gypsum into valuable chemical products and intermediates - EGYVACHEP) and cofunding by VUCHT a.s.

\section{References}

Ahlbeck J, Engman T, Fältén S, Vihma M (1993) Chemical Engineering Science 48: 3479-3484.

Ahlbeck J, Engman T, Fältén S, Vihma M (1995) Chemical Engineering Science 50: 1081-1089.

Benjamin MM (2002) Water Chemistry, McGraw-Hill. ISBN-10: 1577666674.

BP Energy outlook 2018 Edition. https://www.bp.com/ content/dam/bp/en/corporate/pdf/energy-economics /energy-outlook/bp-energy-outlook-2018.pdf

Brown SR, De Vault RF, Williams PJ, Babcock \& Wilcox Power Generation Group Inc. http://www.powermag. com/techniques-for-determining-limestone-composi tion-and-reactivity/? Printmode=1 (2009, accessed 5. 5. 2018)

Chan PK, Rochelle GT (1982) American Chemical Society Symposium Series 188: 75-97.

Claudio A, Carletti G (2015) New Aspects in Limestone Dissolution for Wet Flue Gas Desulfurization, PhD Thesis, Åbo, Finland.

CN101337684A, Method for recovering sulfur and coproducing calcium carbonate from desulfurization gypsum.

Danielik V, Fellner P, Jurišová J, Králik M (2018) Chemical Papers 72: 2631-2639.

De Blasio C, Mäkilä E, Westerlund T (2012) Applied Energy 90: 175-181.

Dou B, Pan W, Jin Q, Wang W, Li Y (2009) Energy Conversion and Management, 50(10): 2547-2553.

Dragan S and Ozunu A (2012) Cent. Eur. J. Chem. 10(5): 1556-1564.

EU Reference Scenario 2016, Energy, transport and GHG emissions, Trends to 2050 (https://ec.europa. eu/energy/sites/ener/files/documents/ref2016_ report_final-web.pdf). 
Exxon Mobil, 2018 Outlook for Energy: A View to 2040 (http://cdn.exxonmobil.com/ $\sim$ /media/global/ files/outlook-for-energy/2018/2018-outlook-forenergy.pdf).

Fellner P, Khandl V (1999) Characterization of Limestone Reactivity for Absorption of $\mathrm{SO}_{2}$ from Fume Gases. CHEMICAL PAPERS-SLOVAK ACADEMY OF SCIENCES, 53: 238-241.

IEA. Energy and Air pollution World Energy Outlook 2016. Special report (2016) (C) OECD/IEA, 2016, International Energy Agency, 9 rue de la Fédération, 75739 Paris Cedex 15, France. (https://www.iea.org/ publication/freepublications/publication/WorldEner gyOutlookSpecialReport2016EnergyandAirPollution. pdf)

Jang HG, Lee GJ, Mo SY (2001) KR100303388.

Jang YN, Ryu KW, Lee MK (2014) US2014161692 (A1) $-2014-06-12$.

Králik M, Balko J, Foltinovič T, Štefancová R, Kučera M, Fellner P, Danielik V, Jurišová J (2017) $44^{\text {th }}$ International Conference of SSCHE, May 22-26, 2017, Demänovská dolina, Slovakia: 662.

Pepe F (2001) Industrial Engineering Chemistry Research 40: 5378-5385.

Plummer LN, Busenberg E (1982) Geochimica et Cosmochimica Acta 46(6):1011-1040.

Olausson S, Wallin M, Bjerle I (1993) The Chemical Engineering Journal 51(2): 99-108.
Shih SM, Lin JP, Shiau GY (2000) Journal of Hazardous Materials B 79: 159-171.

Siagi ZO, Mbarawa M (2009) Journal of Hazardous Materials 163: 678-682.

Stumpf Th, Roeder A, Hennicke HW (1984a) Das Reaktionsverfahren von Carbonatgesteinsmehlen in sauren, insbesondere schwefligsauren Lösungen. Teil I. (in German). Zement-Kalk-Gips 37: 262.

Stumpf Th, Roeder A, Hennicke HW (1984b) Das Reaktionsverfahren von Carbonatgesteinsmehlen in sauren, insbesondere schwefligsauren Lösungen. Teil II. (in German). Zement-Kalk-Gips 37: 454.

Toprac A, Rochelle GT (1982) Environmental Progress 1: $52-58$.

Ukawa N, Takashina T, Shinoda N, Shimizu T (1993) Environmental Progress 12: 238-242.

Wallin M, Bjerle I (1989) Chemical Engineering Science 44: $61-67$.

Wirsching F (2000) Calcium Sulfate. In: Ullmann's Encyclopedia of Industrial Chemistry. Wiley-VCH Verlag GmbH \& Co. KGaA. doi: 10.1002/14356007. a04_555

Ye Z and Bjerle I (1994) Powder Technology 79: 273-277.

Zhong Y, Gao X, Wang H, Luo ZY, Ni MJ, Cen KF (2008) Fuel Processing Technology 89(11): 1025-1032. 